\title{
Report CC-579
}

Metallurgical Laboratory

A. H. Compton, Project Director

* * *

\section{CHERTCAT RESEARCH - RADIOCHENISTRY}

J. Franck, Division Director; C. D. Coryell, Section Chief

$* * *$

REPORT FOR MONTH ENDING APRII 17, 1943

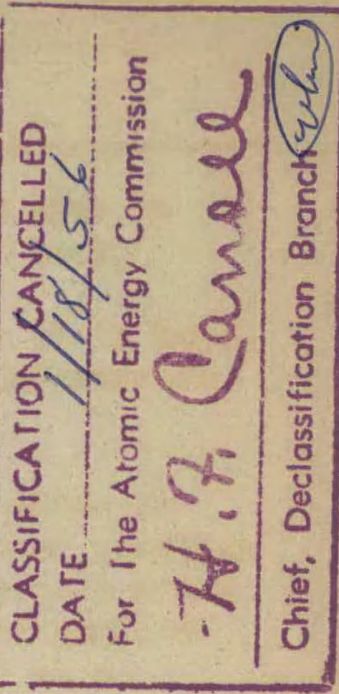

$* * *$

Table of Contents

00. Abstract

0. General Activities of the Section

1. Flenentary Breakdown of Fission Activity in the Pile Operation up to 170 Days

a. Distribution of "Effective $\beta$ Activity"

b. Distribution of "Effective Soft $\gamma$ Activity"

c. Distribution of "Effective Hard $\gamma$ Activity"

2. Heat Generation of Individual $\beta$ and $\gamma$ Activities - L. Winsberg and 7 . Rubinson

3. New Fission Product Activities and Re-evaluation of Old Data

Q. Discovery of $55 \mathrm{~m}$ and $30 \mathrm{~s}$ Rh Activities-Daughters of

$30 d$ and $200 d$ Ru Activities - L. E. Glendenin and

E. P. Steinberg

b. 43 Activities in Fission - L. E. Glendenin

c. Rare Earth Work- Ce in Fission Chains (cont.)

4. Theoretical Study of $\beta$-Absopption Curves and Correlation with

Feather Method of $\beta$-Inergy Determination - T. Novey,

E. Steinberg, N. Ballou, G. CampbelI, and I. Winsberg
Page

1

2

11.

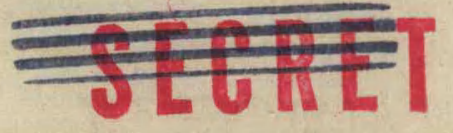

This doetument contrinsinfmation affectitig the nationul defensem inthin tha meaning of the $\rightarrow$

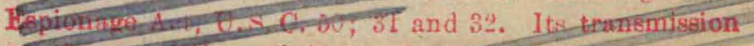
of whe revelation of its contepts in any maaner to an unauthorized person is probffited by law. 


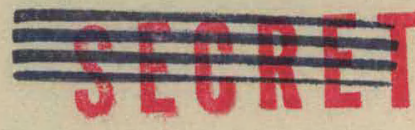

on.

ABSTRACS

1. A continuation of the detajled analysis of $\rho$ and soft and" hard $\gamma$ activity associated vith 017 fission product elements in a nitrate bombardnent is presented. The "cooling" time has been extended to 170 days. The data for the individual elements are presented in tables as counts/min and in figures as percentage of total $\beta$, soft $\gamma$, and haxd $\gamma$ radiations.

2. Calculations and graphs have been made on the heat generated by the longer-lived fission products. The nethod of analysis is presented.

3. Two nev short-lived $\mathrm{Ph}$ fission product activities have been found. They are probably the daughters of the two long Iived Pu activities $(30 d, 200 d)$. Re-evaluation of data on 43 leads to the conclusion that the longest lived 43 activity in measurable yields is the $6.7 \mathrm{~h}$ (formerly $6.6 \mathrm{~h}$ ). Nerr parantcaughter relationships in the rare-edrth activities are given.

4. Theoretical 8 absorption curves have been made using the Femi distribution fumction and 1inear absorption curves for small energy intervals. A Feether analysis of the absorption curve leads to the theoretical maximum energy.

*******

Dr. A. Tuxisevich joined the Section this month as leeder of the group concerned Nith theoretical problens. IIessrs. D. Schover and B. Schloss have entered Dr. IJ. EIlitott's group on electronic development and design: Mr. I. Winsberg, Dr. T.. Rubinson's group on separation problems; ilessrs. J. D. Knight and I. Steinberg, Dr. IN. Sugaman's group on plant problems; and IIr. B. Abraham, Dre. Turikevich's group on theoretical problems.

This document eontains infoumation affecting the nationat, defense of the Inital Stran

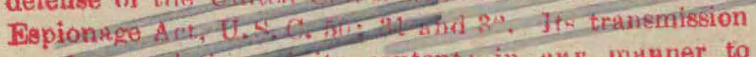
or the revelys its entents in any uxuner to an unathorized pers an is protritsinet bi

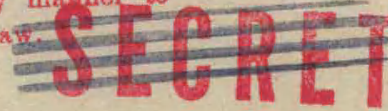




\section{Q. Ceneral Activities of the Section}

A report oin decontamination problems, with special reference to II material, has been prepared by Coryell and issued under the folt, owing heading:

\section{Ch-576 A Consideretion of Decontamination Recruirements}

Mesprs. Gest and Abreham have extended considerably (over section 2 of Cllm528) our knoviledge of the coprecipitition of Ba by Isliz from $10 \%$ nitrete soluttions being used to ovaluate the general. prineiples of coseparatian, and efforts vill be made to study other systems of interest with the same view in mind.

Hot radloective nitrate (S-8 box k) has been furmished to Dre Balthis fore study by the phosphate method. This sectiton is: plenping to malke delbained flssion product analyses of the precipitates for stucties of specifice decontamination of vartous fission eleipents.

Ir collabosetion with Dre Jafiey of Section $C \rightarrow I$ and with the assistinnce Irom Drs, Teller, Fermi, and Hitgner, plans heve been loid for the improtrenent of 19 yield at the Stalowis cyclotaron. On Agrein 16 and 17 Dre, Jafiej, Brom, Krohmen (Section C-I) and

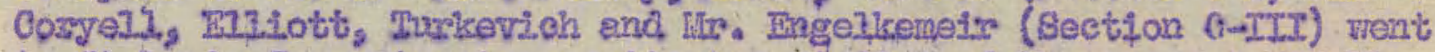
to St.touis foy extensive monitoring studiss of the cuxyent 300 Ib njtrate mass and of projested altergtions involving metril and nitarate

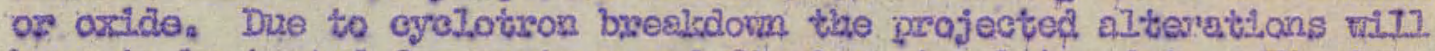
have to be tested for captuze and fission at \& laten datea Fisetion wess measured by the radioactivity accumulating in cellogihane by trecoth from $1 \mathrm{~cm}^{2}$ of motel; $30 \mathrm{~m}$ after a Am imsadition at $50 \mathrm{~min}$ activity of the oxder of $3,000-12,000 \mathrm{c} / \mathrm{m}$ was pbtained $16 \mathrm{~h}$ later an activity of about $200 \mathrm{e} / \mathrm{m}$ mes obtained from a stronger sample. Captitre was measured. by counting the sodium motal, acetate precipititie obtained from a solutian of the same metri. foll.

This document containeinforamation affecting the national defene of the United Stentiag within thit meaning ys the

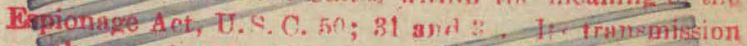

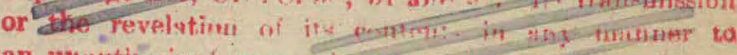

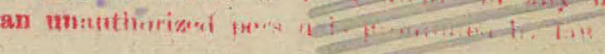




\section{Dilenentery Breajriown of Fission Activity in}

the P11. Operation up to 170 Davs

There is presented below the contrinuation of the study of the distribution of $s$ and $\gamma$ activities found in the $100,000 \mathrm{kah}$ St. Iouis urenyl nitrate bonbardment which ended October 25, 1942 (ca11ed S-5). Earlier data have been reported in Section 1 of $00-342$ I and Section 2 of CC-399 $D_{3}$ and the resulti mere sumarized for the period from 10 to 110 days cooling in Section 2 of CC-465 B.' Data hatre now been obtained. up to 170 days of cooling. In some cases later data have caused slight revistions in the shapes of the best curves through experimental points: the best data are now presented. These changes do not affect any previously reported velues prior to 90 days of conling except in the case of

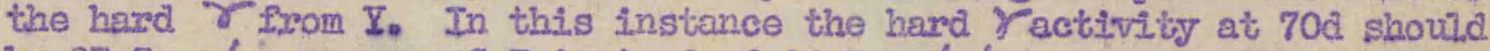
be $27.3 \mathrm{c} / \mathrm{m}$ per gam S-3 instead of $24.7 \mathrm{c} / \mathrm{m} / \mathrm{g}$ as proviously reported. In IIIg. 3 of CC- $165 \mathrm{~B}$ the $I$ curve should pass through the point 1.4 at 70 instead of 7.3 as shom.

Attention Is again called to the corrections that shovld be made in the Ia deta reported in CC-465 B. The Ia line of Table I, page B-5 is incorrect at 70,90 , and 170d. The correct values are the follow ing2

$\begin{array}{rrr}700 & 800 & 7100 \\ 14.8 & 4.9 & 1.7\end{array}$

In Fig. I the compect La curve should be displaced by a constant mount frem the $\mathrm{Ba}$ curve, corresponding to the experimental ratio of 1.25 Ie counts per $\mathrm{Ba}$ count at $11 \mathrm{mg}$ of absorber. The heading in parentheses for Table II in CC-465 B should read "(couniss/min/gm nitirate through I.9 gm/ $\mathrm{cm}^{2} \mathrm{~Pb}$ absorber)" instead of "(counts/min/gm nitrate through $1.9 \mathrm{gm} / \mathrm{cm}^{2}$ $\mathrm{Pb}$ Al absorber)" and elso the carrespondting heading for Table III should read "(counts/min/gm nitrato through 10.7 gm/ $\mathrm{gra}^{2} \mathrm{~Pb}$ absorbor)" :

The values here reported for the $\mathrm{Zr}$ and $\mathrm{Fb}$ activities are based upon a 60d half-life for $\mathrm{zr}$ and a $35 \mathrm{~d}$ half-life for $\mathrm{Cb}$. The Sr activity includes that of the $60 \mathrm{~h}$ У 90 in equilibrium with the Iong 1ived $5{ }^{9}$, reported in CC-529, Section 5 a. i.

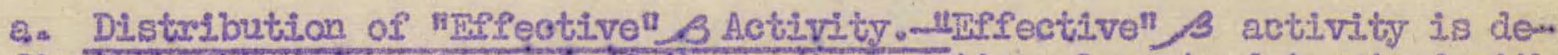
fined as the observed count of the vorious active elements determined nith a total absomption (air gap, cellgphone covering, mica vindor, and self absorption) amounting to $11 \mathrm{ng} / \mathrm{cm}^{2}$, which coxresponds to the minimum winich is practicable. Table I presents the observed values at 20 dey intervals from 90 to 170d. A11 values are reported as counts per minute per gram of S-3.

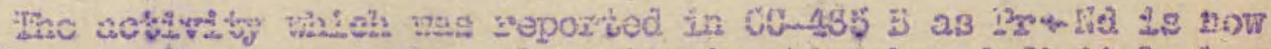

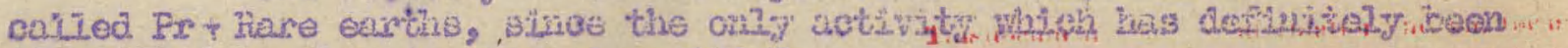
idghtified in this frection is a $150 \mathrm{P} x$. 
It is noted that the percent activity accounted for in Trable I is low at $150 d$ and $170 d$. Due to on oversight, values of pexcent accounted for vere not given in Table I of CC-165B (page B-5) for earlier periods of time. The data for the time nov studied are:

$\begin{array}{llllllllll}\text { Cooling: } & 10 d & 30 d & 50 d & 70 d & 90 d & 110 d & 130 d & 150 d & 170 d \\ \% \\ \begin{array}{l}\text { Accounted } \\ \text { for }\end{array} & 92.6 & 96.3 & 96.0 & 95.7 & 96.9 & 97.7 & 96.7 & 94.9 & 92.3\end{array}$

It is not known at present thother the folling off is due to experimental erros in the low counting rates renaining, or to failure to recognize the prosence of certain long lived elenents. Since tre do not have enough of the S-3 nitrate to mount new samples of the low activities, we shall have to use the activity of the irrociation ended January 23 (S-8) for check and extension rork before tre can eliminate further discrepancies. The percent of effective $\beta$ activity associated. vith each prominent element is given as a function of cooling time from 90-170 $d$ in Fig. 1. After $100 d$ Ce becones the most prominent $\beta$ emitter. The $\mathrm{Cs}$ is slotily gaining in prominence, due to its very long half-life (36y). The 3 emission from $90 d \mathrm{Te}^{127}$ is obviously very soft, since the $\mathrm{Te}$ s decay is largely regulated by the $32 \mathrm{~d} \mathrm{Te}^{129}$ decay. The Be-Ia pair falls to very low values after 120d.

The presentation of the data for "effective" $\beta$ and $\gamma$ counting rates has proved of considerable volue in rapid laboratory studies and controls in the trork of this and other sections, and ought to be of further volue in decontramination studies. It has been pointed out in CC-576 that the data for hord $S$ emitters can be multiplied by 0.5 to give the curies of the element in $V$ materiol containing $250 \mathrm{gm}$ of 49 (2,500 KV material from 100d operation, let us say 1 ton). Correction factors for specific elements emitting soft. 3 or "radiation $(\mathrm{Zx}$ or $\mathrm{Cb})$ are 2l.so given in $\mathrm{CC}-576$. 
b. "Iffective Soft $\chi$ "Distribution - The "effective soft $\gamma$ " counting rate is reported as the counts per minute per grom of $\mathrm{S}-3$ observed ulth 1.9g of $\mathrm{Pb}$ absorber directily on top of the sample. Table II presents the observed values at 20 day intervals from 90 to 170 days and ILg. 2 shous the percent of the observed tatal comt which is due to ench activity.

c. "Effective Hard $\gamma$ " Distribution. -The "effective hard $\gamma$ " counting rate is reported as the counts per minute per gram of S-3 observed with $10.7 \mathrm{~g}$ of $\mathrm{Pb}$ absorber directiy on top of the semple. The contribution due to Bremsstreahlung has not been definitely determined. Table ITI presents the observed volues at 20 day intervals from 90 to 170 days and Fig. 3 shows the \% of the observed totil count which is due to each activity.

The fall in percentage activity accounted for is greater in effective soft and hard $\gamma$ activities after $100 d$ than in $\beta$ activity. It is experimentally much more difficult to get good $\gamma$ semples, and especial effort will be made to cover this in the new work on S-8 nitrate.

Ce becomes the third most prominent soft and hard $\gamma$ emitter after $80 d$ (Figs. 2 and 3 ) due to the high Brensstrahlung yield in the $\mathrm{Pb}$ geometry used. Fu is undoubtediy third in $-\gamma$ in ordinary circumstances. The Te $\gamma$ decay is set largely by the $\gamma$ emitting $90 \mathrm{~d}$ Te 129 . The $\gamma$ radiation from Cs becomes about as important as that of Te aं 1702 .

Table I Distribution of Effective Beta Activity Among the Fission Elements

$\left(10^{-3} \mathrm{x}\right.$ counts/min/grum nitrate through $11 \mathrm{mg} / \mathrm{cm}^{2}$ total absorption) Days after conciusion of bombardment

\begin{tabular}{|c|c|c|c|c|c|}
\hline & 902 & $110 \mathrm{~d}$ & $130 \mathrm{~d}$ & 500 & $170 \mathrm{~d}$ \\
\hline \multicolumn{6}{|c|}{ Flement } \\
\hline Sr & 79 & 59.5 & 44.5 & 34 & 25.3 \\
\hline $\mathbf{Y}$ & 69 & 53 & 42 & 34 & 27.6 \\
\hline $2 x$ & 34.5 & 27.3 & 23.0 & 17.1 & 3.3 .6 \\
\hline $\mathrm{Cb}$ & 9.1 & 8.0 & 7.0 & 6.1 & 5.2 \\
\hline Ru & 10.1 & 8.1 & 6.7 & 5.7 & 5.0 \\
\hline $\mathrm{Te}$ & 2.36 & 1.56 & 1.09 & .78 & ${ }_{.} 57$ \\
\hline Cs & 1.7 & 1.7 & 1.7 & 1.7 & 1.7 \\
\hline $\mathrm{Ba}$ & 3.68 & 1.24 & .42 & .15 & .05 \\
\hline Ia & .4 .9 & 1.68 & .57 & .21 & .07 \\
\hline $\mathrm{Ce}$ & 74.5 & 63 & 55 & 50.5 & 47 \\
\hline$P x+$ & 4.3 & 1.64 & .73 & .41 & .29 \\
\hline
\end{tabular}

Raxe earths

Totors $(a) 299$

232

189

159

137

Accounted for:

$96.9 \%$

$97.7 \%$

$96.7 \%$

$94.9 \%$

$92.3 \%$

(a) The UX contribution has been subtrreted from the measurements on the nitrate. It contributes the constont value of $18,000 \mathrm{c} / \mathrm{m}$ which is a better estimate than the $17,000 \mathrm{c} / \mathrm{m}$ reported in CC $-465 \mathrm{~B}$. 
Mable II) Disuribution of Besective Soft Conma Activity Among the Jispion tomento

(counts/min/gxam nitrete through $1.9 \mathrm{~g} / \mathrm{cm}^{2} \mathrm{~Pb}$ absorber)

Days aftex concluston ox bombarameent

\begin{tabular}{|c|c|c|c|c|c|}
\hline \multicolumn{6}{|c|}{ Elenent } \\
\hline $5 x$ & 210 & 1.40 & 94.5 & 63.5 & 42.5 \\
\hline$I$ & 87 & 68 & 53.5 & 14 & 36.4 \\
\hline $2 x$ & 980 & 780 & 625 & 495 & 395 \\
\hline $\mathrm{Cb}$ & 1370 & 1180 & 2020 & 845 & 710 \\
\hline Ru & 307 & 219 & 162 & 121 & 92.5 \\
\hline Te & 28.3 & 23.4 & 19.4 & 16.2 & 13.5 \\
\hline$I$ & 7 & - & - & - & - \\
\hline $\mathrm{Cs}$ & 16.4 & 16.4 & 16.4 & 16.4 & 36.4 \\
\hline $\mathrm{Ba}$. & 20.4 & 7.2 & 2.6 & .91 & .34 \\
\hline Le? & 184 & 66 & 23.5 & 8.2 & 3.2 \\
\hline $\mathrm{Ce}$ & 315 & 297 & 284 & 274 & 267 \\
\hline \multicolumn{2}{|c|}{$\begin{array}{l}\text { Totals (a) } 3690 \\
\text { Accounted for: }\end{array}$} & 2980 & 2450 & 2730 & 7840 \\
\hline & $95.6 \%$ & $01.2 \%$ & $93,5 \%$ & $89.2 \%$ & 85.78 \\
\hline
\end{tabular}

(a) The experimentnily observod bacturzumd of $50 \mathrm{c} / \mathrm{m}$ per gram of unbomborded. nitrete has been subtractod from the totol.

Table III Distribution of Effective llerd Gama Activity Anong the Fission Hements

(counts/min/gram nitrate through $10.7 \mathrm{~g} / \mathrm{cm}^{2} \mathrm{~Pb}$ absorber)

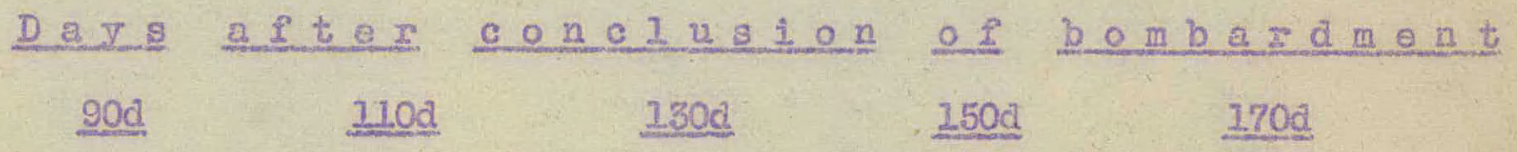

Tizenent

\begin{tabular}{|c|c|c|c|c|c|}
\hline Sr & 120 & 85.5 & 61 & 43.5 & 3L.2 \\
\hline$I$ & 19.8 & 15.3 & 12.5 & 10.4 & 2.0 \\
\hline $2 x^{n}$ & 393 & 309 & 241 & 192 & 151 \\
\hline $\mathrm{Cb}$ & 510 & 450 & 378 & 312 & 252 \\
\hline Fur. & 75 & 54 & 39.5 & 30.2 & 24.2 \\
\hline Te & 10 & 8.4 & 7.3 & e.3 & 5.5 \\
\hline Cs & 5 & 5 & 5 & 5 & 5 \\
\hline$-\mathrm{Ba}$ & 91. & 31.7 & 11.2 & 3.9 & 1.3 \\
\hline $\mathrm{Ce}$ & 139 & 132 & 2.28 & 128 & 126 \\
\hline
\end{tabular}

$\operatorname{Totals}(a)$

$\begin{array}{rrrr}1450 & 1160 & 960 & 815\end{array}$

Accounted for:
$94.0 \%$
$94.2 \%$
$92.4 \%$
$89.7 \%$
$82.3 \%$

(a) The expertmontoliy observed boclground of $20 \mathrm{c} / \mathrm{m}$ per gram of unbombarded nitzate has been subtracted from the total. 
Fiq.l Percent Distribution Beta Radiation

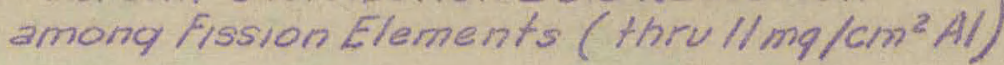

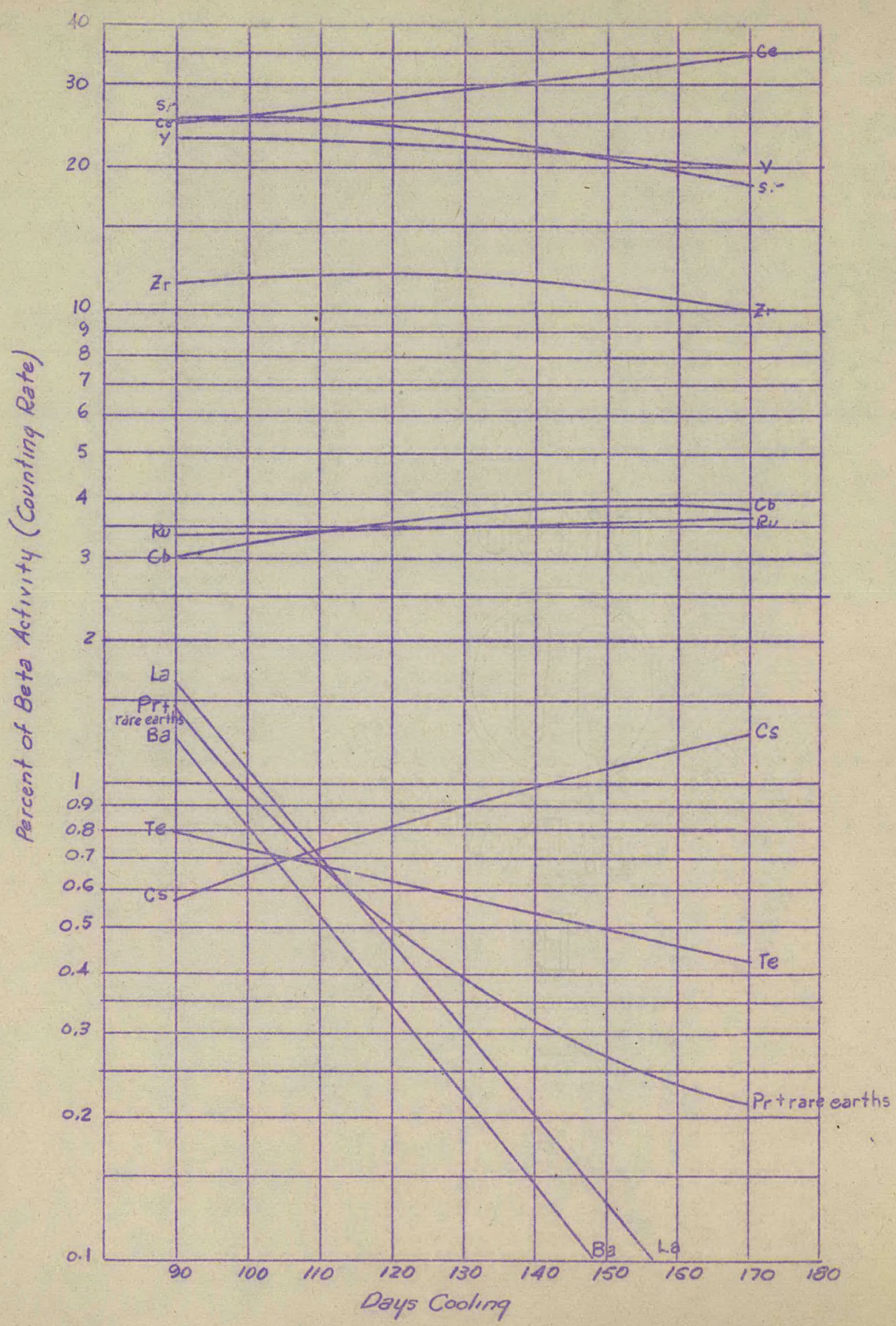


Fig. 2 Percent Distribution "Effective Soft $\gamma$ " Padiation amonq Fission Elements (thru l.9gPb)

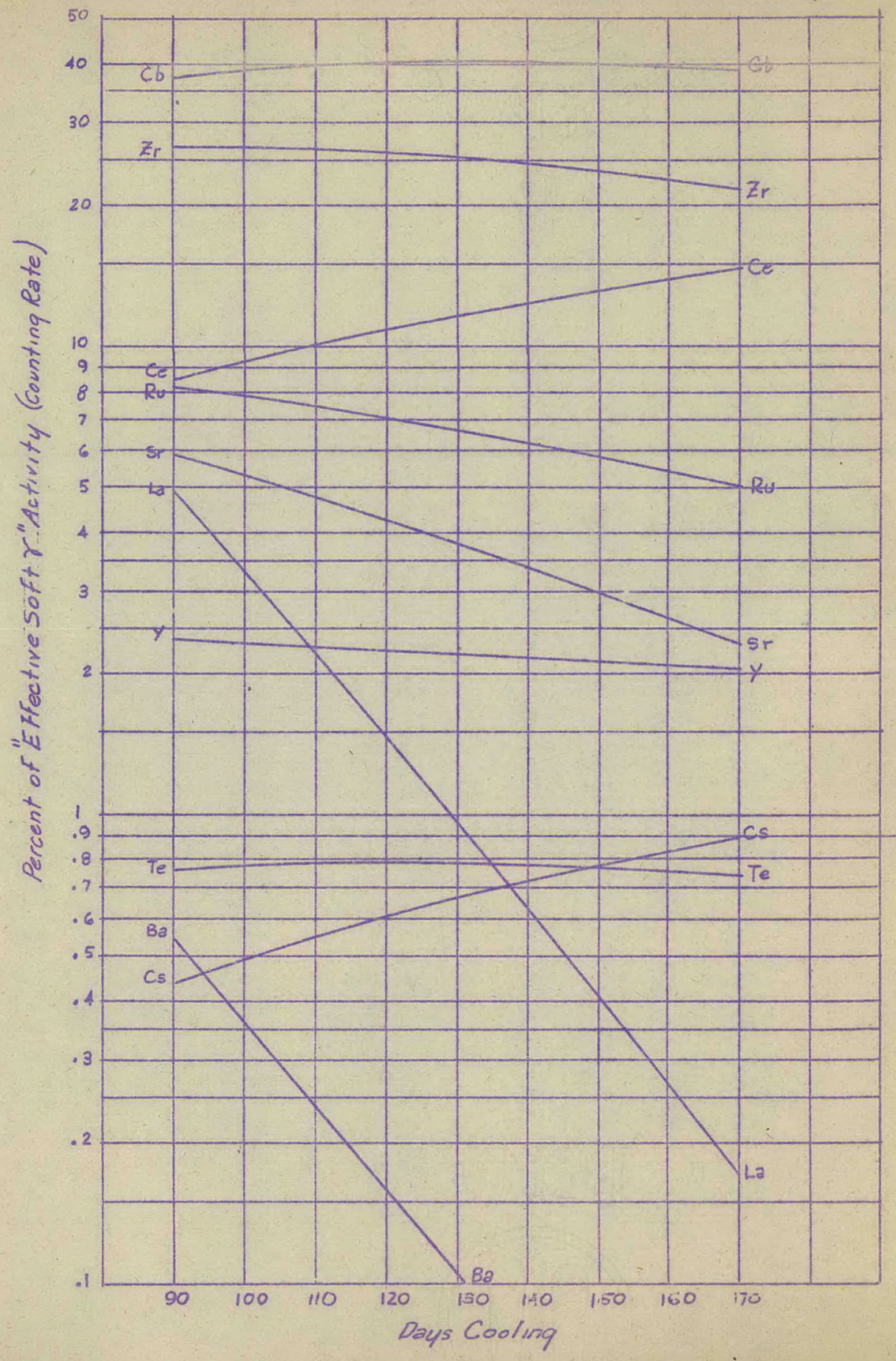


Fig. 3 Percent Distribution of "Eflective Hard $\gamma$ "Radiation among Fission Elementis

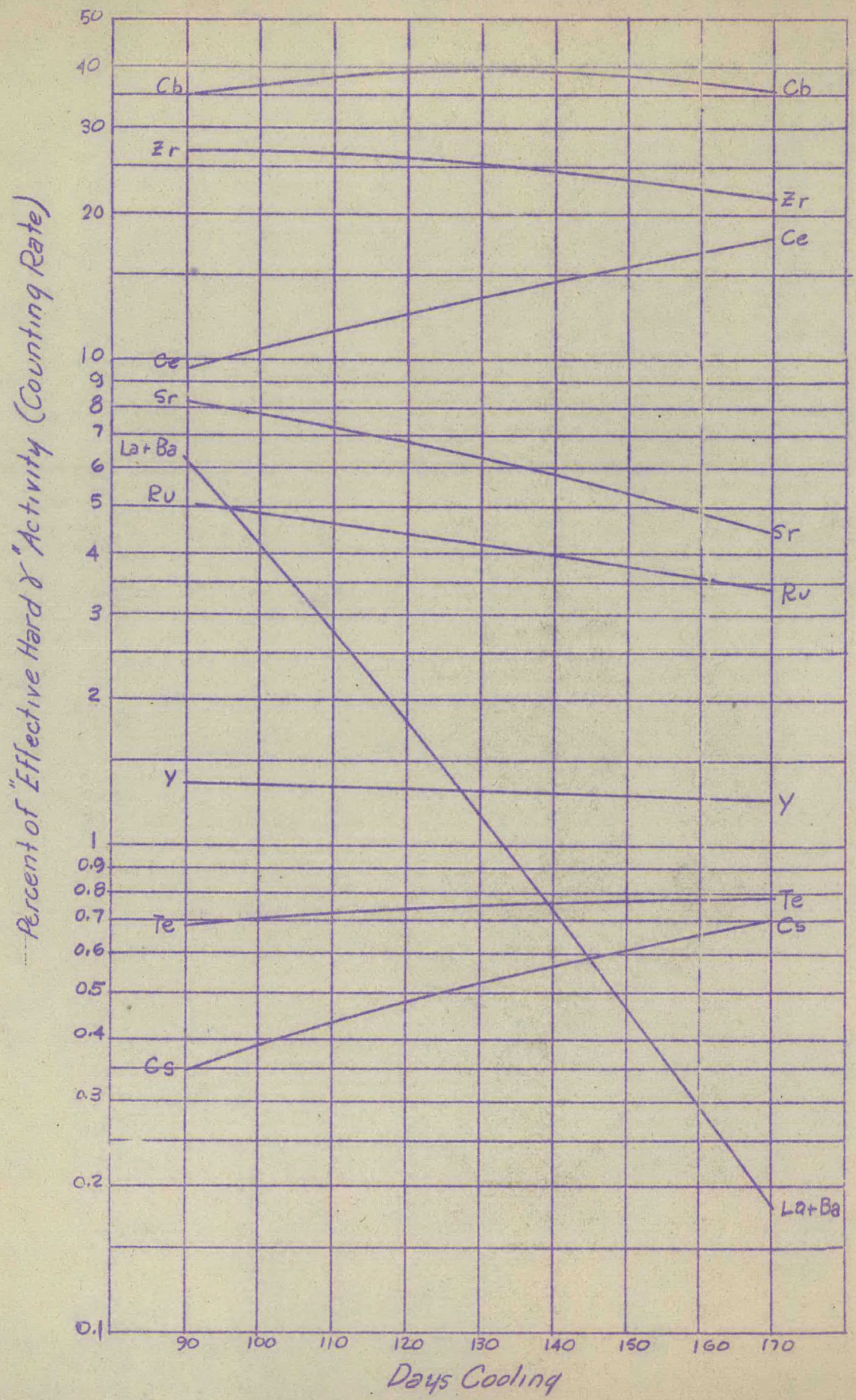


2. Heat Generation of Individuni $\beta$ and $\gamma$ Activities (I. Tinsberg and

Calculations have been made of the heat generation of the different individual $\beta$ and $\gamma$ activities of eight of the most importnnt fission products as a function of bombardment time and time of cooling, and the results graphed as watts vs days. As a basis for cclculation convenient for transformation to any other conditions, we have chosen a pile of $1000 \mathrm{KII}$ power, or $3 \times 10^{16} \frac{\mathrm{dis}}{\mathrm{sen}}$. As bomberdment time, tre have taken $T=5,10,15,20,30,40,50,60,80,100,120,150,200, \infty$ derys. The cooling time is talsen long onough for the activity to fall to one watt.

latest data:

We not have available graphs for the following elements and

\begin{tabular}{|c|c|c|c|c|}
\hline Element & Holf-life & Fission yield & Er & $E_{\beta}(\max )$ \\
\hline $\mathrm{Sr}$ & $55 d$ & .075 & - & 1.7 \\
\hline $\begin{array}{l}7 \\
7 r\end{array}$ & $\begin{array}{l}57 \mathrm{~d} \\
60 \mathrm{~d}\end{array}$ & $\begin{array}{l}.074 \\
.04\end{array}$ & $\overline{0.8}$ & $\int^{1.4}$ \\
\hline$\frac{2 x}{6}$ & $60 d$ & .045 & & \\
\hline $\mathrm{Cb}$ & $35 d$ & .04 & .75 & $.15(e)$ \\
\hline tho & $67 \mathrm{~h}$ & .08 & .8 & 1.5 \\
\hline $\mathrm{Ba}$ & $12.5 \mathrm{~d}$ & .084 & - & 1.0 \\
\hline Iอ & $40 \mathrm{~h}$ & .084 & 2.1 & 1.84 \\
\hline $\mathrm{Ce}$ & $28 \mathrm{~d}$ & .07 & & 0.2 \\
\hline
\end{tabular}

For an element formed directly in fission or deriving from a short-lived parent:

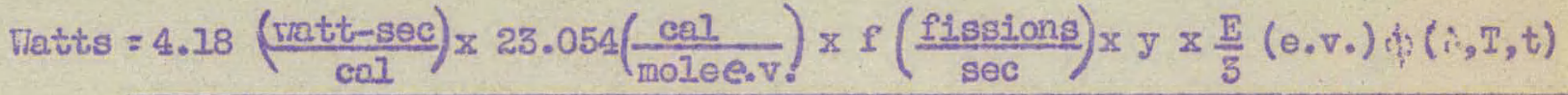

$$
\begin{aligned}
& 6.02 \times 10^{23}
\end{aligned}
$$

$=1.60 \times 10^{3} \mathrm{y} \mathrm{E} \phi(\lambda, \mathrm{T}, t)$, where $b$ is a time dependent function, $f$ is the number of fissions/sec, $y$ is the fission yield and $\mathrm{E}$ is the maximum energy of the $\beta$ particle. $1 / 3 \mathrm{E}$ is assumed to be the average $\beta$-energy. For $\gamma$ radiations the factor $1 / 3$ is omitted.

For an element the life of those parent must be token into account the constent factor is different:

$$
\begin{aligned}
\text { Watts } & =\frac{4.18 \times 23.054 \times f \times \mathrm{y} \times \frac{\mathrm{E}}{3}}{6.02 \times 10^{25}\left(\lambda_{p}-\lambda \lambda\right)} \psi\left(r, t, \lambda_{p}, \lambda 1\right) \\
& =1.60 \times 10^{3} \frac{\mathrm{g} T}{\lambda_{p}-\lambda_{d}} \cup\left(r, t, \lambda_{p}, \lambda()\right.
\end{aligned}
$$


3. INew Fission Product Activities and Ro-evalvation of 01d Data

a. Discovery of $55 \mathrm{~min}$ and $30 \mathrm{sec}$ Rh activities-Daughters of $30 \mathrm{~d}$ and 200 d $\mathrm{Tu}$ Activities (I. I. Glendenin and E. P. Steinberg) - In view of the extremely hard 8 radiation (4 Ilev) associated with the $200 d$ Ru activity a search was. made for an anticipated short-lived $\mathrm{Rh}$ daughter. to account for this penetreting radiation. A very active sample of Ru separated from S-8 material (St.Louis bombardment onding Jan. 23, 1943) and containing $-10^{6} \mathrm{c} / \mathrm{m}$ (at $30 \%$ geometry) of $30 \mathrm{~d}$ Ru activity mas distilled from . $\mathrm{HClO}_{4}$ - $10 \mathrm{mg}$ of $\mathrm{Cd}$ carrier was added to the residue and $\mathrm{Cd}(\mathrm{OH})_{2}$ precipitated with 6IJ NaOH. This precipitate which corries Rh was mounted and the decay followred on an Eck-Krebs counter. A 55 minute period was observed for several hours which finaliy tailed-off to a long-lived background. This background activity was first assumed to be incompletely distilled Fu, but an A7 absorption curve showed that this was not the case. Two radiations with half-thiclmesses of $. .10 \mathrm{mg} / \mathrm{cm}^{2}$ and $\sim 70 \mathrm{mg} / \mathrm{cm}^{2}$ trere present in the long-lived activity. I.jither of these corresponds to any knowm $\mathrm{Ru}$ activity so the beckground activity remains unidentified. An A] absorption curye of the $55 \mathrm{~min} R \mathrm{Rh}$ indicated a radiation of $T^{\frac{1}{2}}=-80 \mathrm{mg} / \mathrm{cm}^{2}$ as mell as $\gamma$ radiation. The activity of the 55 min Rh extreapolated to time of separation mas $\cdots \quad 30,000 \mathrm{c} / \mathrm{m}$ which represented $\sim 3 \%$ of the $30 d$. Ru activity or $-15 \%$ of the $200 d$ Ru.

The experiment wies repeated on a Ru sample from S-2 materiol. (St.Iouis bomberdment ending July 22, 1942). The activity of this sample was $-10,000 \mathrm{c} / \mathrm{m}$ (at 30\% geometry) and consisted entirely of the 200d. isotope. No decay in activity was observed in the $\mathrm{Cd}(\mathrm{OH})_{2}$ precipitated. from the distillation residus. The $55 \mathrm{~min}$ Rh is evidently not the daughter of $200 \mathrm{~d} \mathrm{Ru}$. The parent is very probobly the 30d Ru. The decay curve of the $55 \mathrm{~min}$ Ph is given in Fig. 4 .

Following the discovery of the 55 min $R h$ a method was devised for finding a very short-lived. Rh daughter of the $200 \mathrm{~d}$ Ru activity. The S-8 Ru somple mentioned above wes distilled from $\mathrm{HClO}_{4}$, and the residue in the distillation flask placed immediately near a Geiger counter. Two minutes elapsed from the beginning of distillation to the beginning of the decay curve. Consequentily about one minute of decay time vas lcst. A 30 second decey period was observed over severol half Iives. The activity then tailed-off to a constant value due to a small. amount of inconpletely distilled Ru. It is now evident that the 4 liev $A$ radiation is ascribable to the $30 \mathrm{sec} \mathrm{Rh}$ and that the radiation of the $200 \mathrm{~d}$ Ru parent is so weals that it is not observed. However, there is some evidence from absorption deta on the 200d Fin taken in a Ior absorption counting device (with $0.3 \mathrm{mg} / \mathrm{cm}^{2}$ of self-absorption) for the existience of a rudiation of $<10 \mathrm{mg} / \mathrm{cm}^{2}$ range. Further vorks will be carried out on older materiol in which the only Pu activity is the $200 d$ activity to definitely prove the parent-daughter relationships. Decay and growth curves of the 30 see $\mathrm{Bh}$ are given in Fig. 5 and $5 \mathrm{a}_{\text {. }}$

b. 43 Activities in Fission (I. E. Glendenin) - In previous work it was

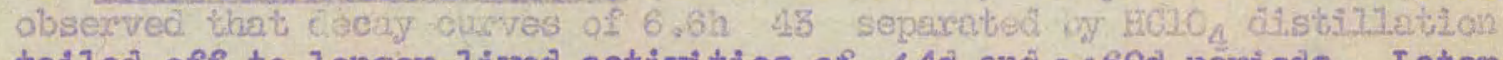
talled-off to longer-lived activities of $-4 d$ and $\sim 60 \mathrm{~d}$ periods. Later work (cf CC-529) showed that the 60d activity was not due to elenent 45 but probably due to $R u$ contamination. It is now evident that the $\sim 4 d$ activity is also due to contamination chiefly by $67 \mathrm{~h}$ Ho which follows element 43 in small quantities in the distillation method of 43 separation. 


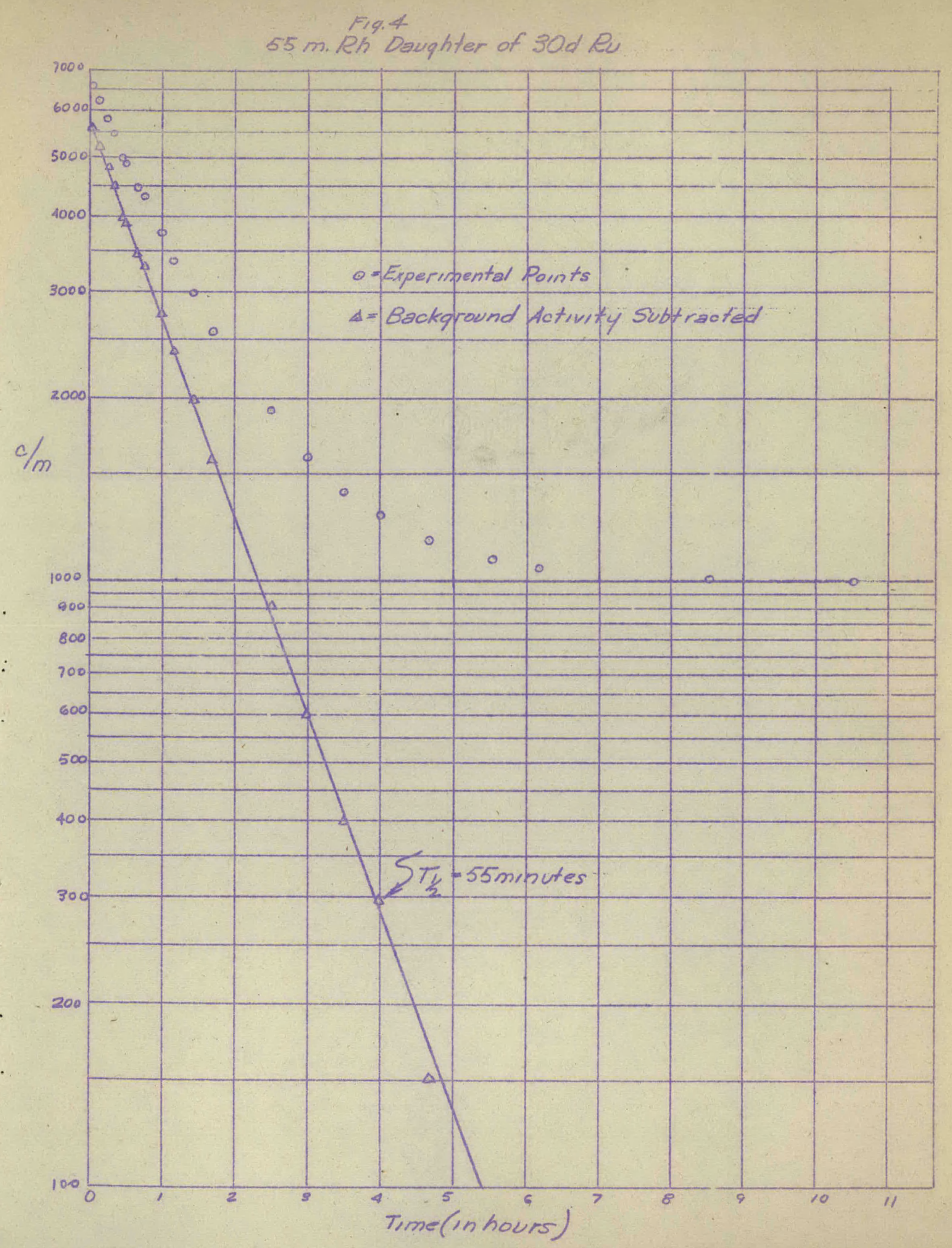




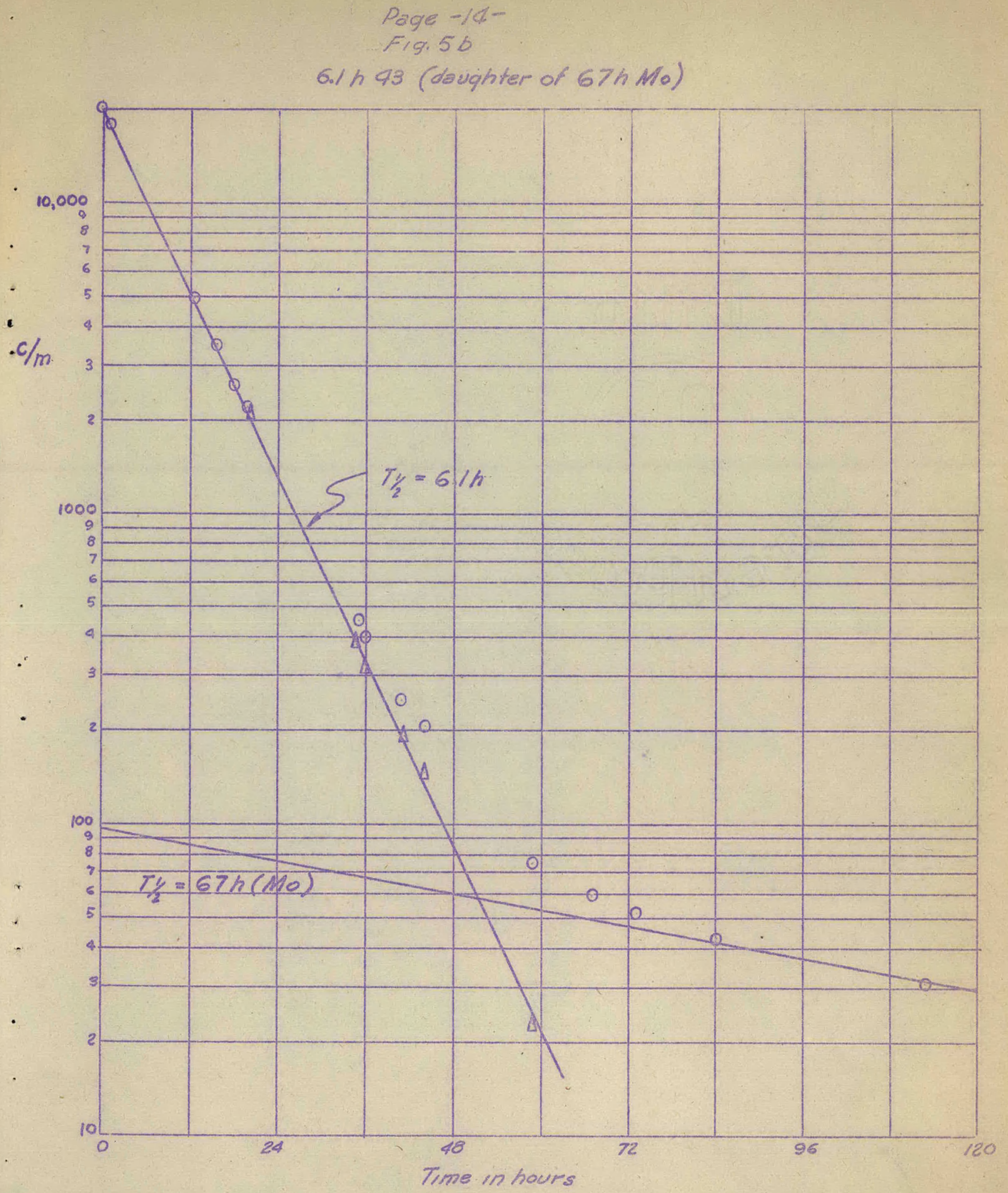


A Ru $S_{5}$ prectpitation waß made from $25 \mathrm{gm}$ of $\mathrm{S}-17$ material (St.Louis bombredmont ending Hex.13,1943). Whis was dissolved in aque regie and distilled from $\mathrm{HClO}_{4}$. The disti37nte vas bollod with ethanol. which

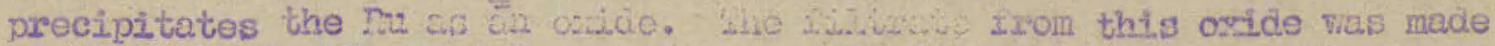
$\sim 5 \mathrm{~N}$ in $\mathrm{H}_{2} \mathrm{SO}_{4}, 5 \mathrm{mg}$ of Re carrier was added, and Regirn preciptitated with His. The RegSip was dissolved in a Iittile aqua regia, and a nitron perrhenate precipitation nade. This precipitate nas dissolved in hot 5I! $\mathrm{H}_{2} \mathrm{SO}_{4}$, and $\mathrm{Re}_{2} \mathrm{~S}_{7}$ reprecipitated with $\mathrm{H}_{2} \mathrm{~S}$. The sample was mounted and its decay followed closely. The $6.6 n 43$ tailed-off to a $\sim 3 d$ activity and finalyy to a much longer-lived beckground. The $\sim 3 \mathrm{~d}$ activity represented $\sim 0.5 \%$ of the totol 43 activity at time of separation, and the long-lived beckground mis $0.02 \%$ of the initial 43 activity. Then this bacliground was extrepolated and subtracted from the decay curve, the $3 d$ activity was found to be $66 \mathrm{~h}$ vhich suggested that it wes 67h Ho. An Al absorption curve of the $66 \mathrm{~h}$ component showed that it ras indeed the $67 \mathrm{~h}$ [Io. Dvidently, smal]. quantities of lio either distil with Ru and 43 or are carried over in sprey and coprecipitate with the 43. The Iow intensit ty long-lived activi. ty is probably a slight contamination by Ru. It is seen from this work that there is no activity present other than the $6,6 \mathrm{~h}$ ascribable to element 43 . Our best value for the halllife of 43 based on several decoy curves of 43 from fission material is 6.1. $\pm 0.2 h \quad\left(F^{\circ} g, 5 a\right)$.

\section{c. Ce in Fission Chains (cont.) (N. E. Ballou) - Studies to determine} the parentage of the Ce activities are bing continued.

A sample of the nitrate vras imadiated with slow neutrons for $50 \mu$ ah on Hiarch 31, 1943 and the La fraction was rapidly isolated (according to procedure of report CC-258). Successive Ce exirractions were made from this Ia fraction at intervals of some hours, and the decay curves followed. These curves are quite complex, but they indicate that both the $1.8 \mathrm{~h}$ Ce (which has a 4.5h $\mathrm{Pr}$ daughter) and the $28 \mathrm{~d} \mathrm{Ce}$ (which forms a stable Pr), have Ia perents of 1 hour or longer. It wil1 be necessary to follow the curves longer before definite assignnents of parentage of the $1,8 \mathrm{~h} \mathrm{Ce}$ and the $28 \mathrm{~d}$ Ce can be made.

Attention should be called to the report by II. I. Pool and J. D. Kurbatov, appearing in the Bulletin of the Anerican Physical Society, 18, 9 (1943), on the various Ce activities from cyclotron bombardment. They obtained a $30 \mathrm{~d} \mathrm{Ce} \mathrm{Ce}^{141}$ which goes to stable Pri.1, and a $36 \mathrm{~h}$ $\mathrm{Ce}^{143}$ which decays to $13.5 \mathrm{~d} \mathrm{Pr}^{143}$. These half-lives and isotopic assignments ogree with previous mork done by us and reported in CC-529, CC-465, and CC-389. They also obtained a 140d $\mathrm{Ce}^{* 120}$ which decays by isomeric transition with the emission of a 0.21 . Mer $\gamma$ to

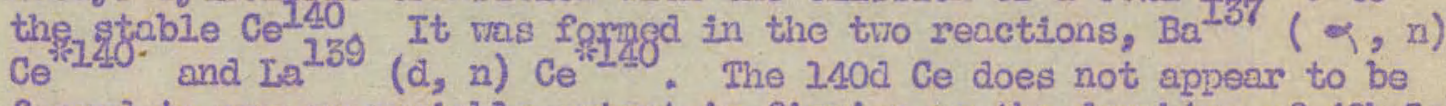
formed to any eppreciable extent in fission as the daughter of $10 \mathrm{~h} \mathrm{Ia}^{140}$. Glendenin has followed a zamma decay curve of $12.5 \mathrm{~d} \mathrm{Ba}$ (rihich is the parent of $40 \mathrm{~h} \mathrm{La}$ ) through $1.9 \mathrm{gm}$ of $\mathrm{Pb}$ for about 3 months. It was calculated that about $60 \%$ of the totel observed activity at the end of this 3 month period would be due to Ce $e^{340}$ if it were formed in this chain. In the calculations the effect of $1.9 \mathrm{gL}$ of $\mathrm{Pb}$ on the counting efficiency of the 0.2 IIev was taken into consideration. Since the decay curve did not flatten out, $140 \mathrm{~d} \mathrm{Ce}^{* 140}$ is not formed in appreciable exient as the daughter of $40 \mathrm{~h} \mathrm{Ia}^{140}$. 
4. Theoretion Study of -Absomption Gurmes and Comrelation with Feother Method ofB-inergy Determination (T. Ilovey, Li. Steinbert, il. Ballor,

G. Campbell, and I. Winsberg)-Theoreticol curves for the $\rho$ energy distributions for various meximum $\beta$ energy vere obteined from the Fermi theory of $\&$-disintegretion. These curves have been used to estjmate the average S energy corresponding to a given meximum ss energy. Tyler (Phys.Rev.56, 125, 1939) has shorm the volidity of the Fermi distribution curve for the S radiation from thin samples.

Wie have also been interested in correlations between range and energy. The absorption curve for monoenergetic electrons is nearly linear with absorber thiclmess; using the theoreticals distribution curves calculated, a synthetic absorption curve can be nade for a $s$ emitter. Tie have done this belor, using the Sargent rvnge-energy relation (Coryell, Seuborg Lecture Notes CL 440). This curve is closely similar to the experimental RaE curve obtained in our apparatus (CC-529, section 3 a i) which we use in the Feether Method for analjzing, 3 obsorpition curves (CC-529, section 3 b).

The probubilitu, $\Pi_{3}$, for the emission of electrons of energy in the range $\mathrm{E}$ to $\mathrm{E}+\mathrm{d} \mathbb{\mathrm { E }}$ is given by the Fermi thoory as:

$$
W=A B^{2} \quad(L+2 E)(1+E)^{\frac{1}{2}}(E-E)^{2} d E
$$

where $A$ is a constont for a given activity, $E$ is the $\beta$-enexgy, and In is the maximura $s$-energy, both expressed in Mev. This equation is an approximate one, good to $-2 \%$ (Po.llard \& Davidson, Applied Iviclear Physics, App.4). A loss excect, but simpler, equation, good to within 15\% for values of E less thon 2 llev is:

$$
\pi=B(E)(3+2 E)(E-E)^{2} d E
$$

Where $B$ is a constant for any one activity. The constants $A$ and $B$ are chosen to normalize the distribution function, i.e.,

$$
\int_{0}^{\frac{\pi n}{\pi}}=1
$$

The $A$ distributions for $\mathrm{E}$ mox $=0.5,2,2,3$ liev were colculated from the second formula and are given in Fig. 6. The most probible energy is found to be proportional to the maximum energy, being at 4 of the range. The average energy was also calculated and was found to be 0.42 of the maximum energy Arom In $=0.5$ Her to $\mathrm{Em}=3 \mathrm{IIev}$ 。 
In calculating the absorption curves from the distribution curves, it was assumed that for smell energy intervals the absorption in $A 7$ would be linear. That this is almost true for monoenergetic electrons in AI except near the range is shom in some work done by Ti. Wi1son as given by Rutherfored, Chadrick, and Filis, p.414 (1930). The fact that the tail of the curve falls off the linear curve is of no great concern since the center of the absorption curve is the most important part for $s$-energy determinations.

Iinear absorption curves were drawn for small energy intervals taking the value of $W$ as the activity at no absorber and the Sargent value of the range for the particular energy interval under consideration. The total absorption curve was then obtained by adding these individual curves for the small energy intervals and is given in Fig. 7 A.

One calculation of an absorption curve using the more exact Fermi equation was made for In $=1$ litev. This is the lower curve in Fig. $7 \mathrm{~A}$ from which it is seen that no great error is introduced by using the less exact equation.

The absorption curve was then subjected to a Feather analysis (Fig. 7 B), i.e., compared with the RaE absorption curve by the method outlined in CC-529, section $3 \mathrm{~b}$ and in p.54 of CL- 440 . The data give a surprisingly good brealcdom by this method, particularly since it has been shom that the shape of an $A 7$ absorption curve of a $\beta$ emitter is a function of the counting geometry (Fig.3-3 of report CC-529). (It must be recalled that we have based our synethetic absorption curve approxinately on the geometry used by Varder with absorbers placed in the electron path in the magnetic spectrograph giving monoenergetic beans.)

The average range shom in $\mathrm{Tig} .7 \mathrm{C}$ is $430 \mathrm{mg} / \mathrm{cm}^{2}$ (broken horizontol line) which corresponds to a meximum $\beta$ energy of 1.09 llev (Feather range-energy curve Fig. A of $\mathrm{G}-200$ or GL-440). This Feather energy is higher than any Sargent $\beta$ energy assumed. The maximum range by the Sargent curve is hovrever $430 \mathrm{mg} / \mathrm{cm}^{2}$ for 1.0 [lev. The extrapol.ated range (continuous curve of the figure) leads to the reange $380 \mathrm{mg} / \mathrm{cm}^{2}$, corresponding to a maximum energy of $0.99 \mathrm{Llev}$.

In Cc-529 (section 3b) we adopted for the present the convention of averaging the Fouther range over the fructions of range observed. The empirical nature of the symthetic curve of Fig. $7 \mathrm{C}$ prevents its use as an argument against this convention. Further work is in progress in the field of analysis of / curves. 
Fig. 6 fermi distribution curves for varraus ralues of $E$ max.

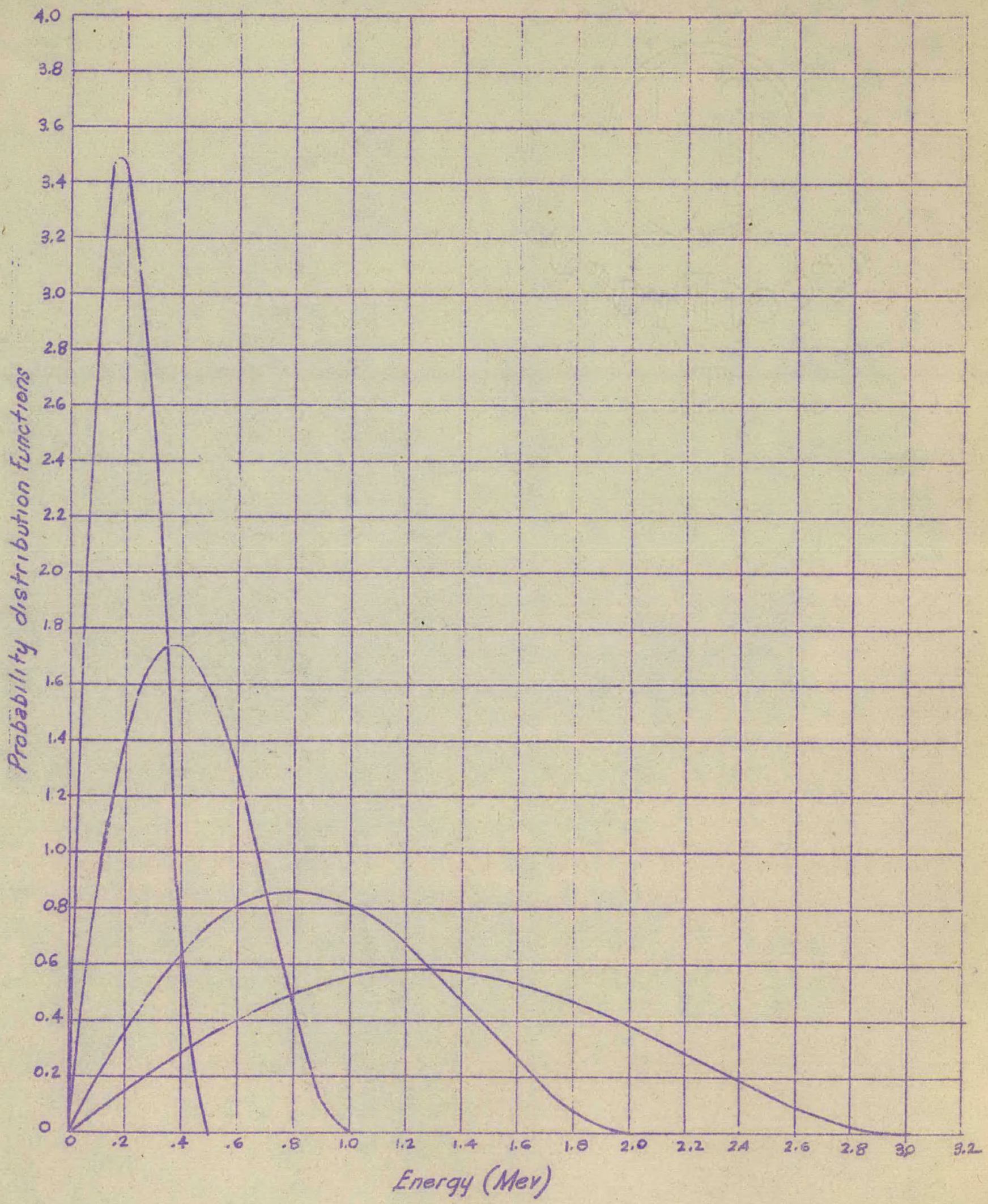


Theoretrcal Absorption Curves for 1 , Me it is

Jargent Range $420 \mathrm{mgAl} / \mathrm{cm}^{2}$

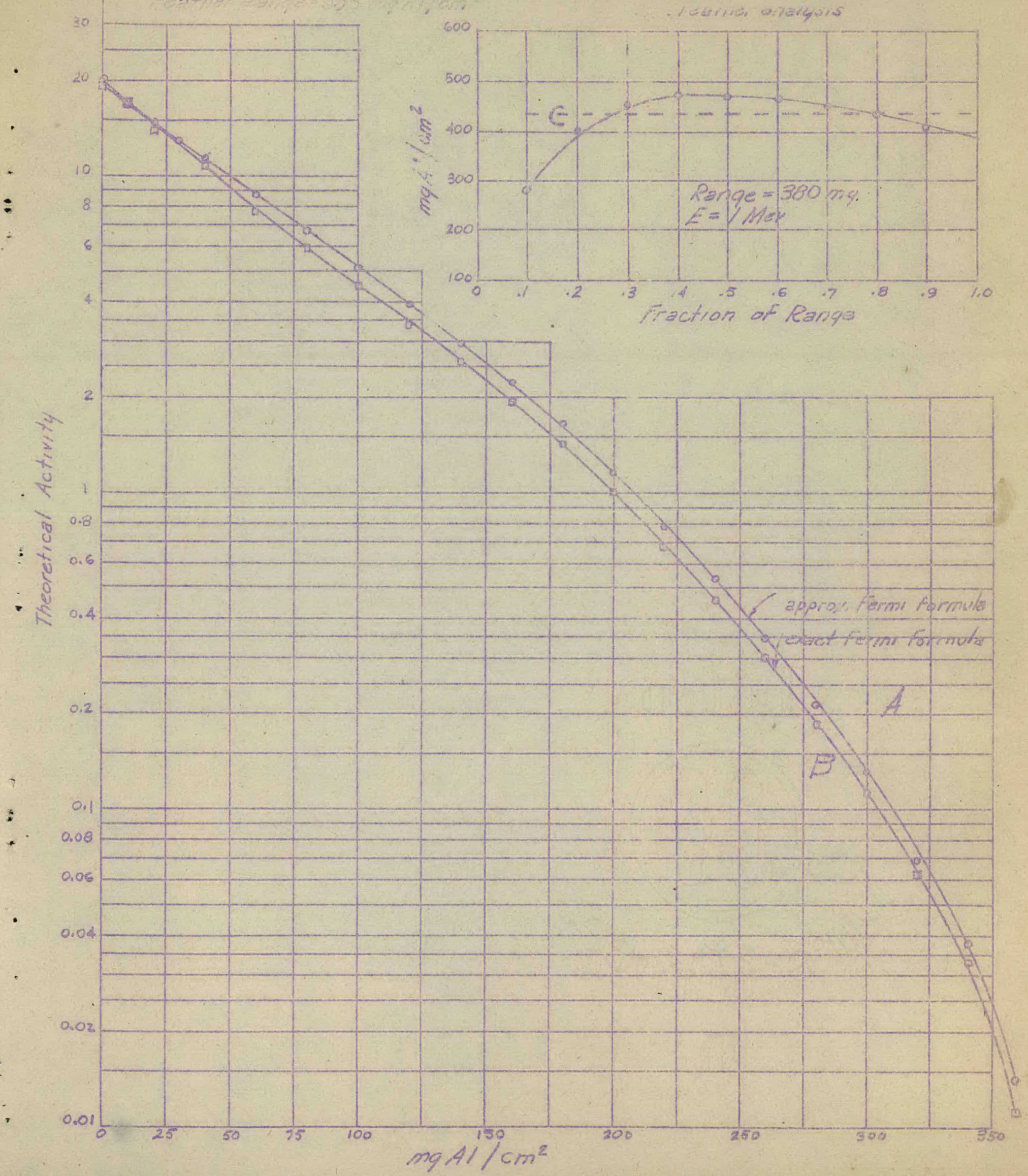

